\title{
TDP-43-specific Autoantibody Decline in Patients With Amyotrophic Lateral Sclerosis
}

Anne Kallehauge Nielsen, MSc, Jonas Folke, PhD, Sylwia Owczarek, PhD, Kirsten Svenstrup, MD, PhD, Kristian Winge, MD, PhD, Bente Pakkenberg, MD, DMSc, Susana Aznar, PhD, and Tomasz Brudek, PhD

Neurol Neuroimmunol Neuroinflamm 2021;8:e937. doi:10.1212/NXI.0000000000000937

\section{Abstract}

\section{Objective}

We hypothesize alterations in the quality and quantity of anti-43-kDa TAR DNA-binding protein (TDP-43) naturally occurring autoantibodies (NAbs) in patients with amyotrophic lateral sclerosis (ALS); therefore, we assessed relative binding properties of anti-TDP-43 NAbs composite in plasma from patients with ALS in comparison with healthy individuals.

\section{Methods}

ELISA competition assay was used to explore the apparent avidity/affinity of anti-TDP-43 NAbs in plasma from 51 normal controls and 30 patients with ALS. Furthermore, the relative levels of anti-TDP-43 NAbs within the immunoglobulin (Ig) classes of IgG (isotype IgG1-4) and IgMs were measured using classical indirect ELISA. The occurring results were hereafter correlated with the measures of disease duration and disease progression.

\section{Results}

High-avidity/affinity anti-TDP-43 NAbs levels were significantly reduced in plasma samples from patients with ALS. In addition, a significant decrease in relative levels of anti-TDP-43 IgG3 and IgM NAbs and a significant increase in anti-TDP-43 IgG4 NAbs were observed in ALS plasma vs controls. Furthermore, a decrease in global IgM and an increase in IgG4 levels were observed in ALS. These aberrations of humoral immunity correlated with disease duration, but did not correlate with ALS Functional Rating Scale-Revised scores.

\section{Conclusions}

Our results may suggest TDP-43-specific immune aberrations in patients with ALS. The skewed immune profiles observed in patients with ALS could indicate a deficiency in the clearance capacity and/or blocking of TDP-43 transmission and propagation. The decrease in levels of high affinity/avidity anti-TDP-43 NAbs and IgMs correlates with disease progression and may be disease predictors.

\author{
Correspondence \\ Dr. Brudek \\ tomasz.brudek@regionh.dk
}

From the Research Laboratory for Stereology and Neuroscience (A.K.N., J.F., S.O., B.P., S.A., T.B.), and Department of Neurology (K.S., K.W.), Bispebjerg-Frederiksberg Hospital, University Hospital of Copenhagen; Neuromuscular Clinic (K.S.), Department of Neurology, Rigshospitalet, Copenhagen; Institute of Clinical Medicine (B.P.), Faculty of Health and Medical Sciences, University of Copenhagen; and Copenhagen Center for Translational Research (S.A., T.B.), Copenhagen University Hospital, Bispebjerg and Frederiksberg, Denmark. 


\section{Glossary}

ALS = amyotrophic lateral sclerosis; ALS-FRS-R = ALS Functional Rating Scale-Revised; BSA = bovine serum albumin; Ig = immunoglobulin; $\mathbf{N A b}=$ naturally occurring autoantibody; $\mathbf{N C}=$ normal control; $\mathbf{P B S}=$ phosphate-buffered saline; $\mathbf{R T}=$ room temperature; TDP-43 = 43-kDa TAR DNA-binding protein.

The etiology in most amyotrophic lateral sclerosis (ALS) cases remains elusive, with only approximately $10 \%$ of all cases being familial and linked to specific pathogenic mutations. ${ }^{1,2}$ The neuropathology of ALS is characterized by aggregation of insoluble 43-kDa TAR DNA-binding protein (TDP-43) in the cytoplasm of degenerating motor neurons and glia cells. ${ }^{3,4}$ The precise mechanism of TDP-43 aggregation is unknown but is associated with an abnormal accumulation of fulllength, truncated, hyperphosphorylated, and/or ubiquitinated TDP-43 species in the cytoplasm. ${ }^{5-8}$ Patients with ALS present increased levels of TDP-43 in CSF and plasma. ${ }^{9}$ Extracellular pathogenic TDP-43 species, including aggregation seeds, result from cell death but can also be released from cells to CSF via exosomes. ${ }^{10,11}$

Abundant and autoreactive immunoglobulin (Ig) G and IgM naturally occurring autoantibodies (NAbs) are normal components of the blood and play an important physiologic role in maintaining tissue and protein homeostasis through adaptive debris clearance. ${ }^{12,13}$ NAbs recognize and bind self-antigens before the acquired immunity becomes activated. ${ }^{14}$ Evidence from other neurodegenerative diseases suggests altered levels of NAbs being implicated in the impaired clearing of pathologic proteins. ${ }^{15-17}$ IgG autoantibodies can also exhibit antiinflammatory capacities, depending on their IgG subclass (isotype IgG1-4). ${ }^{18-20}$

Abnormalities in the peripheral immune system have been documented in patients with ALS. ${ }^{21}$ Results from our study show immune alterations specific for TDP-43 in patients with ALS. Thus, we hypothesize that these alterations are universal for sporadic ALS and have pathologic effect on the TDP-43 clearing mechanism.

\section{Methods}

\section{Participants and Samples}

All patients with ALS were followed by a specialist at the motor neuron disease team, Department of Neurology, Bispebjerg-Frederiksberg Hospital, Copenhagen, Denmark. The diagnosis of ALS was performed according to the revised El Escorial criteria for the diagnosis of ALS. ${ }^{22}$ Thirty patients with sporadic ALS were included in the study. Clinical characteristics of all patients with ALS are summarized in table 1, and the clinical details for each individual patient are presented in table e-1 (links.lww.com/NXI/A364). Three patients were still alive at the end of the study, and one was lost due to emigration. ALS Functional Rating Scale-Revised (ALS-FRS-R) was found retrospectively for 23 patients. All samples were withdrawn from the Movement Disorder Biobank at Bispebjerg-Frederiksberg Hospital, Copenhagen, Denmark. All blood samples were collected in EDTA-coated polypropylene tubes and spun at $2,000 \mathrm{~g}$ for 10 minutes at $4^{\circ} \mathrm{C}$. The supernatant plasma was immediately aliquoted and stored in $400 \mu \mathrm{L}$ polypropylene tubes at $-80^{\circ} \mathrm{C}$ until use. No difference in storage time between groups was observed. Normal control (NC) volunteers were free of conditions that might affect the nervous system and did not receive any medical treatment modulating the immune system. There was a statistical difference in age between patients with ALS and NCs. On average, NCs were younger than the patients with ALS $(p<0.001)$. Written informed consent was received from all participants before inclusion in the study according to the World Medical Association Declaration of Helsinki.

\section{Measurement of Anti-TDP-43 Antibodies Using Competitive ELISA}

Affinity/avidity of anti-TDP-43 NAbs was measured by competitive ELISA. Ninety-six-well polystyrene microtiter plates (Nunc MaxiSorp flat-bottom 96-well plate) (\#44-240421; Invitrogen, Carlsbad, CA) were coated with $1 \mu \mathrm{g} / \mathrm{mL}$ recombinant TDP-43 monomer (\#ATGP2093, NKMAX BIO) in ice-cold $0.1 \mathrm{M}$ carbonate buffer ( $\mathrm{pH} 8.5$ ) overnight $\left(>12\right.$ hours) at $4^{\circ} \mathrm{C}$. The plates were blocked for 2 hours at room temperature (RT) with $3 \%$ bovine serum albumin (BSA) fraction V (\#10735078001; Roche, Basel, Switzerland) $+0.1 \%$ Tergitol (\#NP40S; Sigma-Aldrich, St. Louis, MO) solution in phosphate-buffered saline (PBS, pH $7.4100 \mu \mathrm{L}$ per well) and washed 5 times with PBS $+0.05 \%$ Tween-20 (\#P1379; Sigma-Aldrich). Fifty microliters of diluted plasma $(1: 2,000$ in PBS $+0.1 \%$ BSA $)$ were transferred to the plates and incubated for 1 hour at RT. For the competition reaction, plasma samples were incubated before transfer onto plates for 1 hour with TDP-43 monomer at a range of concentrations: 2,$000 ; 1,000 ; 500 ; 250 ; 125 ; 62.5 ; 31 ; 16 ; 8 ; 4$; and $0 \mathrm{nM}$ for competition curve with plasma pools, and 2,000; 200; 40; 8 ; 1.6; and $0 \mathrm{nM}$ for individual samples (the range of TDP-43 monomer concentrations was chosen based on preliminary experiments). After 5 washes with PBS $+0.05 \%$ Tween-20, 50 $\mu \mathrm{L}$ of horseradish peroxidase-labeled polyclonal goat antihuman IgG (Fc fragment specific; \#ab98595; 1:10,000; Abcam, Cambridge, UK) was added and incubated at RT for 2 hours. The plates were washed 5 times, and $50 \mu \mathrm{L}$ tetramethylbenzidine liquid peroxidase substrate (T8665; SigmaAldrich) was added, followed by incubation in the dark at RT for 30 minutes. The reaction was then stopped with $50 \mu \mathrm{L}$ of 0.5 sulfuric acid (\#109073; Merck, Kenilworth, NJ), and the absorbance at $450 \mathrm{~nm} / 620 \mathrm{~nm}$ was measured on a Fisher 
Table 1 Demographic and Clinical Data

\begin{tabular}{|c|c|c|c|}
\hline Demographic segmentation & Patients with ALS $(n=30)$ & NCs $(n=51)$ & $p$ Value \\
\hline Age at the sample, $y^{a}$ & $63.4(11.5)[34-81]$ & $46.12(14.5)[23-90]$ & $<0.001^{b}$ \\
\hline Sex, $F / M^{c}$ & $17 / 13$ & $37 / 14$ & 0.1 \\
\hline Disease onset, y $(n=30)$ & $62.1(11.6)[33-80]$ & - & - \\
\hline Disease duration at the sample, $y(n=30)$ & $1.2(1.08)[1-4]$ & - & - \\
\hline Age at death, y $(n=26)$ & $64.9(10.1)[38-81]$ & - & - \\
\hline Disease duration, y $(n=26)$ & $3.4(1.4)[1-7]$ & - & - \\
\hline ALS-FRS-R $(n=23)$ & $37.6(7.2)[22-47]$ & - & - \\
\hline
\end{tabular}

Abbreviations: ALS = amyotrophic lateral sclerosis; ALS-FRS-R = ALS Functional Rating Scale-Revised; NC = normal control.

Results are presented as mean $( \pm S D)$ range [min-max].

a Student $t$ test.

${ }^{\mathrm{b}}$ Significantly different.

'Chi-squared test.

Scientific Multiskan FC Microplate Reader (Thermo Fisher Scientific, Waltham, MA).

IgGs from plasma samples were purified using the Pearl IgG Purification kit (Cat. no. 786-798; Bioscience, St. Louis, MO). The ELISA assays were performed as described above. For the competition reaction, purified IgG samples were incubated before transfer onto plates for 1 hour with TDP-43 monomer at a range of concentrations: 2,$000 ; 200 ; 66 ; 22 ; 12.5 ; 7.3 ; 2.4$; $0.81 ; 0.27 ; 0.09 ; 0.03 ; 0.01$; and $0 \mathrm{nM}$ for competition curve with $\operatorname{IgG}$ pools $(5,10,25 \mu \mathrm{g} / \mathrm{mL})$, and $200 ; 20 ; 2 ; 0.2 ; 0.02$; and $0 \mathrm{nM}$ of TDP-43 for individual IgG samples $(25 \mu \mathrm{g} / \mathrm{mL})$ (the range of TDP-43 monomer concentrations was deduced from competition curve).

For control experiments, plates were coated with TDP-43 at $1 \mu \mathrm{g} / \mathrm{mL}$, Tau (rPeptide \# T-1001) at $1 \mu \mathrm{g} / \mathrm{mL}$, and $\alpha$-synuclein (rPeptide \# S-1001) at $5 \mu \mathrm{g} / \mathrm{mL}$. For competition, the following range of concentrations was used: 2,$000 ; 66 ; 22$; 7.3 ; $2.4 ; 0.81 ; 0.27$; and $0 \mathrm{nM}$. The ELISA assays were performed as described above.

\section{Measurement of Antigen-specific Autoantibodies}

Relative levels of anti-TDP-43 NAbs of IgG subclasses (IgG14) and IgMs were assessed using in-house developed, indirect ELISA setups. Ninety-six-well polystyrene microtiter plates (Nunc MaxiSorp flat-bottom 96-well plate) (\# 44-2404-21; Invitrogen) were coated with $50 \mu \mathrm{L}$ recombinant TDP-43 protein monomers $1 \mu \mathrm{g} / \mathrm{mL}$ in ice-cold $0.1 \mathrm{M}$ carbonate buffer ( $\mathrm{pH} 8.5$ ) overnight $\left(>12\right.$ hours) at $4^{\circ} \mathrm{C}$. Next, the plates were blocked for 2 hours at RT with PBS + 3\% BSA + 0.1\% Tergitol, pH $7.4100 \mu \mathrm{L}$ per well and washed 5 times with PBS $+0.05 \%$ Tween-20. Fifty microliters of diluted plasma samples in PBS + $0.1 \%$ BSA were added to the plates and incubated for 1 hour at RT. The plasma dilutions were for IgG total 1:1,000 in PBS + 0.1\% BSA; IgG1: 1:50 diluted in PBS + 0.1\% BSA; IgG2 1:200 diluted in PBS + 0.1\% BSA; IgG3 1:100 diluted in PBS + 0.1\% BSA; IgG4 1:100 in PBS + 0.1\% BSA; and IgM 1:200 in PBS + $0.1 \%$ BSA. After a subsequent washing step, the plates were incubated for 2 hours at RT with $50 \mu \mathrm{L}$ of biotinylated secondary antibodies: goat anti-human total $\operatorname{IgG} 1: 30,000$ (\#SAB3701279; Sigma-Aldrich), goat anti-human IgM 1:5,000 (\#B1265; Sigma-Aldrich), mouse anti-human IgG1 1:1,000 (\#1856854; Invitrogen), mouse anti-human IgG2 1:5,000 (\#B3398; Sigma-Aldrich), mouse anti-human IgG3 1:500 (\#B3523; Sigma-Aldrich), and mouse anti-human IgG4 1:200 (\#B3648; Sigma-Aldrich). After washing, $50 \mu \mathrm{L}$ diluted streptavidin-peroxidase 1:10,000 (\#5512; Sigma-Aldrich) was added and incubated for 30 minutes at RT. The plates were washed before the enzymatic reaction was developed by adding $50 \mu \mathrm{L}$ of tetramethylbenzidine and incubated in dark for 30 minutes at RT. The reaction was terminated by addition of 0.5 $\mathrm{N}$ sulfuric acid, and the optical density was measured on a MultiscanTM FC Microplate reader (Fisher Scientific) at 450 $\mathrm{nm} / 620 \mathrm{~nm}$. All samples were normalized to a positive calibrator control in a 2 -fold serial dilution with primary monoclonal mouse anti-TDP-43 antibody (\#ab57105; Abcam) and detected with a secondary biotinylated anti-mouse IgG antibody (\#BA-9200; Vector, Burlingame, CA).

\section{Measurement of Global Antibody Plasma Levels}

Levels of global antibody concentrations in plasma samples were measured using the commercially available Ready-SETGo! ELISA kits (Thermo Fisher Scientific) following the manufacturer's instructions. Plasma samples were diluted in assay buffer supplied with the kits. The dilutions were then empirically determined at the following concentrations for IgG1 ELISA kit 1:2,000 (\# 88-50560); IgG2 ELISA kit 1: 500,000 (\# 88-50570); IgG3 ELISA kit 1:40,000 (\# 8850580); IgG4 ELISA kit 1:1,000 (\# 88-50590); IgG total ELISA kit 1:500,000 (\# 88-50550); and IgM ELISA kit 1: 20,000 (\# 88-50620). 

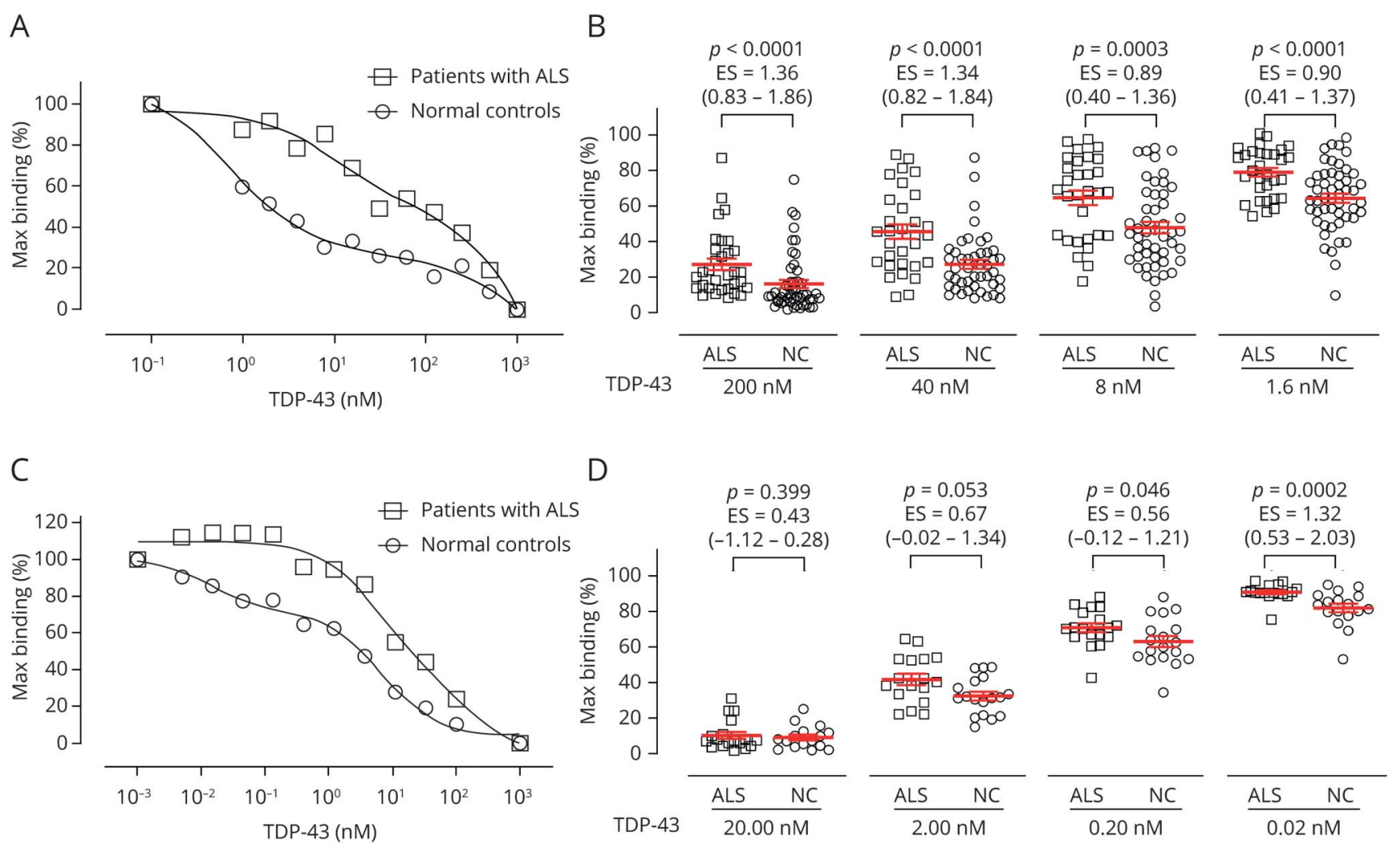

The 2-site inhibition curves (A and C) and individual data (B and D) show distinct high and low binding components in plasma from patients with amyotrophic lateral sclerosis (ALS, squares) and normal controls (NCS, circles). Ten age-matched plasma samples from each group were pooled and incubated with increasing concentration of TDP-43 monomer with subsequent measurement of free NAbs by ELISA. (A) Pooled plasma (C) IgG plasma fraction. Binding of anti-TDP-43 NAbs in (B) individual plasma samples from patients with ALS $(n=30)$ and NCs $(n=51)$ and (D) IgG plasma fractions from patients with ALS ( $n=20)$ and NCs $(n=20)$ to immobilized TDP-43 monomer $(1 \mu \mathrm{g} / \mathrm{mL})$ in competitive ELISA assay in the presence of free TDP-43. The relative binding of anti-TDP-43 NAbs is expressed as a percentage of maximal binding attained in the assay for each sample, where competition reactions with 1,000 nM TDP-43 monomers are defined as constituting nonspecific (background) binding, and reactions without competition, 0 nM TDP-43 monomers, reflect $100 \%$ (maximum) binding. The line represents the fitting of a 2 -site model to the data. Horizontal bars represent the mean values \pm SEM, ES $=\mathrm{Cohen}$ effect size $(95 \% \mathrm{CI})$. Differences between groups were tested using the Student $t$ test or Mann-Whitney $U$ test. Ig = immunoglobulin; NAb = naturally occurring autoantibody; TDP-43 = 43-kDa TAR DNA-binding protein.

\section{Determination of TDP-43 Concentration and IgG- and IgM-/TDP-43 Immunocomplexes}

Concentrations of TDP-43 in plasma were measured with the commercially available TDP-43 Elisa Kit (\# KE00005; Proteintech, Chicago, IL) and used in accordance with the manufacturer's instructions. Plasma samples were diluted with sample diluent solution (1:5), whereas detection antibodies were diluted with detection diluent solution. The data were fitted on 4-parameter logistic $\left(1 / \mathrm{y}^{2}\right.$ weighted) curve used for calculating TDP-43 concentration in samples. For measurements of immunocomplexes, we used Human TDP-43 Elisa Kit from Proteintech (\# KE00005) but replaced the detection antibodies with goat anti-human IgG (1:40,000, \# SAB3701279; Sigma-Aldrich) and goat anti-human $\operatorname{IgM}$ (1:10,000, \#B1265; Sigma-Aldrich). The detection of the signal was performed as described above.

\section{Sample Analyses}

Data obtained from competitive ELISA assays are expressed as maximum of binding on the displacement curve, with exceptions of the fixed extreme points on the curve. The extreme points are the competition reactions of $2,000 \mathrm{nM}$ TDP-43 monomer defined as $0 \%$ binding (representing unspecific binding) and the reactions without competition defined as $100 \%$ binding (representing specific binding).

\section{Statistics}

GraphPad prism software program version 6 (GraphPad Software Inc., La Jolla, CA) was used for statistical analyses of the data. The data were tested for normal distribution using the D'Agostino-Person normality test. Data were tested for outliers using the ROUT method that detects outliers with a false discovery rate $Q=1$. The Student $t$ test was used if the data followed normal distribution. Unequal variances were tested using an $F$ test, and the Welch $t$ test was used for groups having unequal variances. The Mann-Whitney $U$ test was used for data that did not pass normal distribution. The effect size was calculated by Cohen $\mathrm{d}$, being considered as trivial $(-0.2 \leq$ $d \leq 0.2)$, small $(-0.5 \leq d<-0.2$ and $0.2<d \leq 0.5)$, moderate $(-0.8 \leq d<-0.5$ and $0.5<d \leq 0.8)$, and large $(d<-0.8$ and $d>$ $0.8) .^{23}$ The statistical differences were accepted with $p$ values $<0.05$. Analysis of the competition binding curves was 
A. Coating with TDP-43, competition with Tau

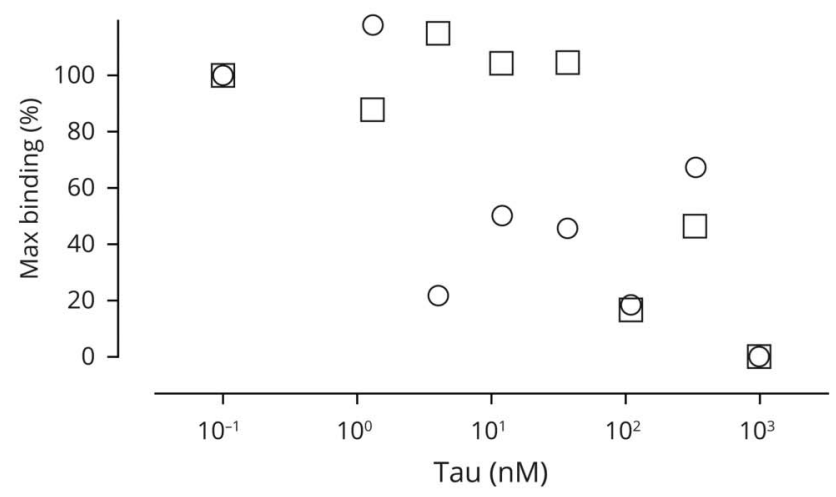

C. Coating with TDP-43, competition with a-synuclein

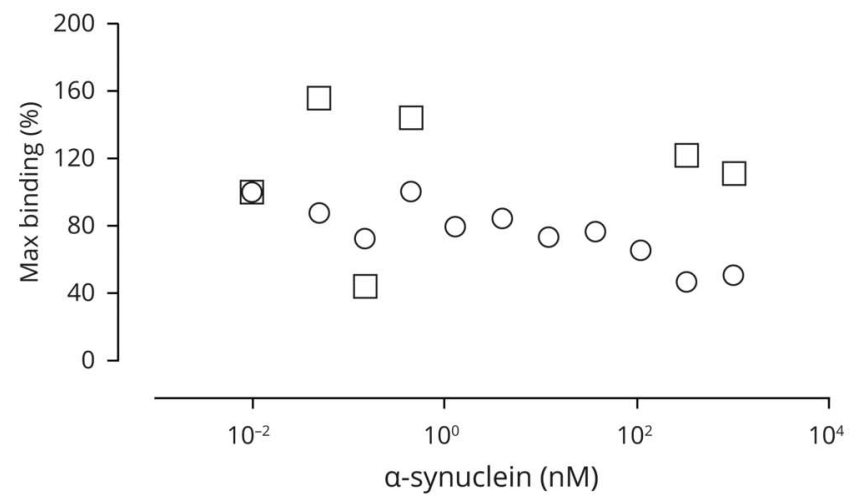

B. Coating with Tau, competition with Tau

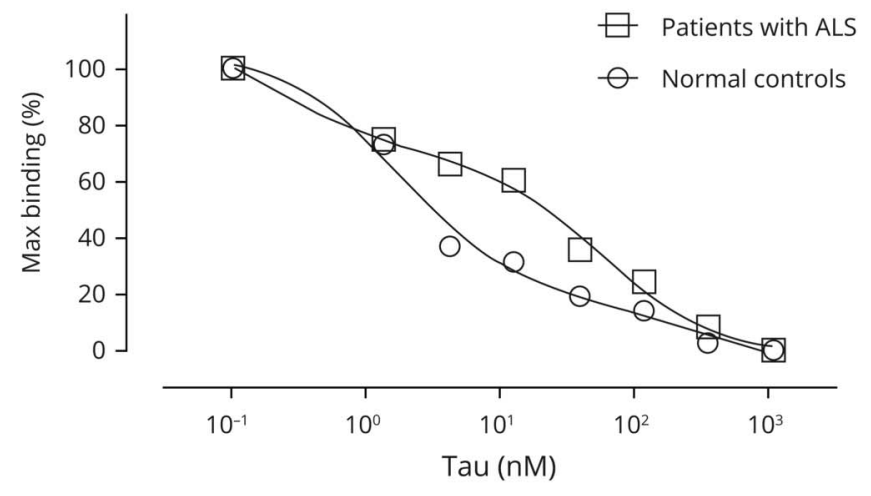

D. Coating with a-synuclein, competition with a-synuclein

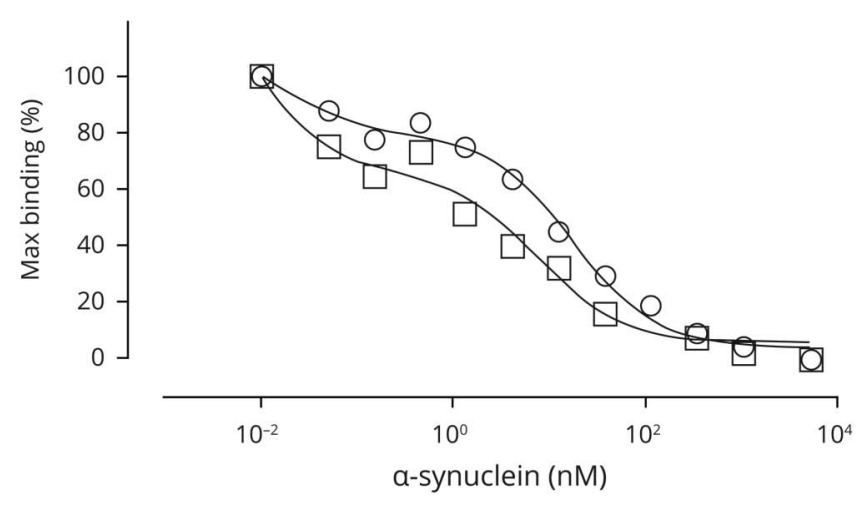

The ability of increasing concentrations of ( $A$ and $B$ ) tau monomers or ( $C$ and $D$ ) $a$-synuclein monomers to inhibit the binding of NAbs to (A and C) TDP-43, (B) tau, and (D) a-synuclein-coated ELISA plates. The relative binding of NAbs is expressed as a percentage of maximal binding attained in the assay for each sample, where competition reactions with $1,000 \mathrm{nM}$ of the respective protein monomer are defined as constituting nonspecific (background) binding, and reactions without competition, $0 \mathrm{nM}$ TDP-43, reflect 100\% (maximum) binding. The line represents the fitting of a 2-site model to the data; 10 randomly chosen patients with amyotrophic lateral sclerosis (ALS, squares and 10 age-matched normal controls (NCs, circles). NAb = naturally occurring autoantibody; TDP-43 = 43-kDa TAR DNA-binding protein.

performed according to the 1- and 2-site models using the computer-assisted curve fitting Fit logIC50 model. Correlation analyses were performed using Spearman nonparametric correlation for non-normally distributed data.

\section{Study Approval}

This study was approved by the Ethical Committee of the Capital Region of Denmark (H-16021964).

\section{Data Availability}

Data presented in this report will be made available to research investigators on reasonable request to the corresponding author.

\section{Results}

\section{Altered Binding Properties of Anti-TDP-43 NAbs in Patients With ALS}

To measure relative binding properties of anti-TDP-43 NAbs composite in plasma, we adapted the competitive ELISA setup as described previously. ${ }^{24}$ Before all analyses, the integrity of the commercial, recombinant TDP-43 protein was validated by Western blotting (figure e-1, links.lww.com/ NXI/A364), showing that the protein is intact and has not been truncated during storage and handling. Results from pooled plasma samples from 10 patients with ALS and 10 agematched NCs showed a distinct apparent affinity/avidity profiles of anti-TDP-43 plasma NAbs (figure 1A). To ensure that the signal is not a result of unspecific binding from unspecific plasma components, we purified IgG fraction (figure 1C) and performed a similar experiment. Based on both binding curves, we separated anti-TDP-43 NAbs into lowand high-affinity fractions. The high-affinity/avidity fraction was characterized by efficient inhibition of antibody binding in the presence of low (1-50 and 0.01-5 nM) concentration of TDP-43 (figure 1, A and C), whereas low affinity/avidity components are exposed at high concentrations of TDP-43 (50-2,000 and 5-2,000 nM, respectively; figure 1, A and C). The displacement curves from NC plasma samples fit the 2-affinity state model. This indicates that a substantial fraction 

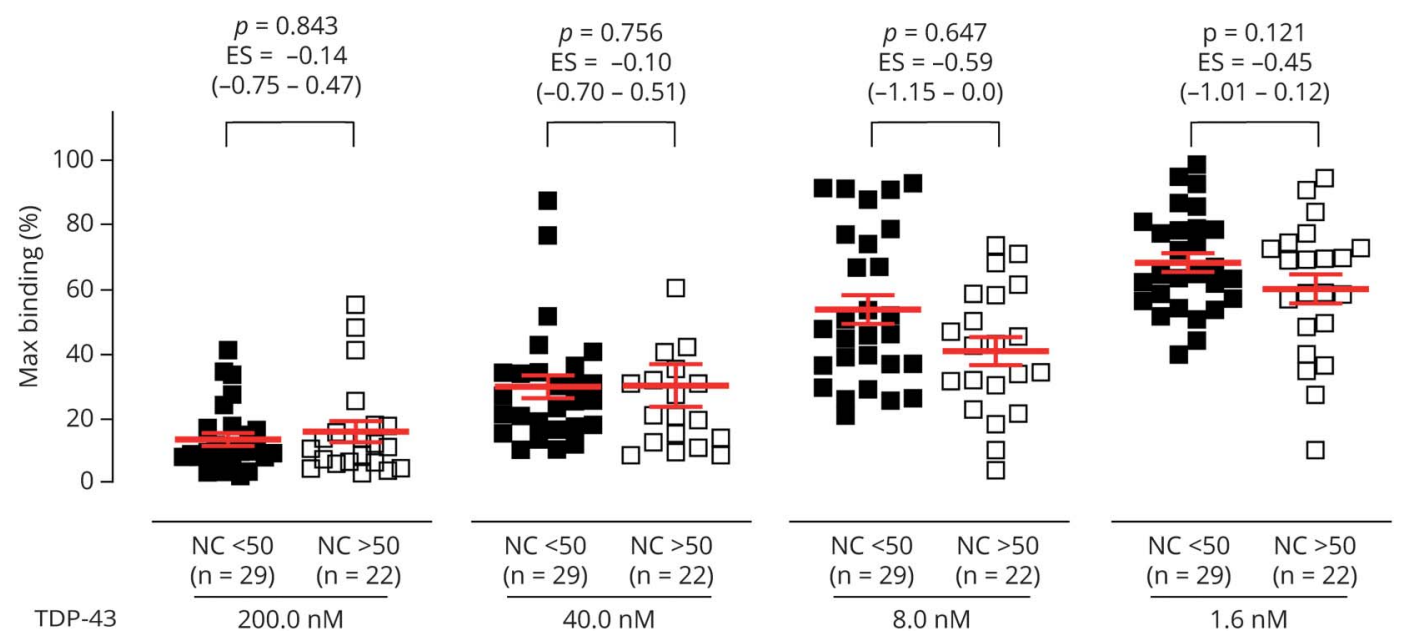

Percentage of maximal plasma NAbs binding to immobilized TDP-43 monomer $(1 \mu \mathrm{g} / \mathrm{mL}$ ) in younger controls (aged $<50$ years, $\mathrm{n}=29$ ) and in elderly controls (aged $>50$ years, $n=22$ ) determined by competitive ELISA assay with 200, 40, 8, and $1.6 \mathrm{nM}$ of free TDP-43, where 2,000 nM defines the nonspecific binding and no free a-synuclein monomer gives the maximal binding. Horizontal bars represent the mean values $\pm \mathrm{SEM}$, ES $=$ Cohen effect size $(95 \% \mathrm{Cl})$. Differences between groups were tested using the Student $t$ test or Mann-Whitney $U$ test. NAb = naturally occurring autoantibody; TDP-43 = 43-kDa TAR DNA-binding protein.

(approximately 50\%) of total antibody binding is characterized by antibodies with high apparent affinity/avidity. However, ALS plasma samples exhibited reduced levels of high affinity antibodies because they required higher TDP-43 concentrations for efficient inhibition of antibody binding compared with samples from NCs.

Next, we tested the relative affinity/avidity of anti-TDP-43 NAbs in the individual plasma samples from 30 patients with ALS and $51 \mathrm{NCs}$ (figure 1B). For each tested concentration of free TDP-43, a mean binding obtained for anti-TDP-43 NAbs in plasma from patients with ALS was significantly higher compared with NCs, indicating that plasma samples from healthy controls contained a significantly larger proportion of high-affinity anti-TDP-43 NAbs compared with patients with ALS.

In parallel, we conducted similar ELISA setups to test the binding properties of purified IgG fractions from randomly selected plasma samples of 20 patients with ALS and 20 agematched NCs (figure 1D). Similarly, to plasma samples, the purified IgG fractions from patients with ALS had significantly reduced binding capability for TDP-43 monomer in comparison with purified IgG fractions from NCs. In the presence of low TDP-43 concentrations, the mean maximal binding for antiTDP-43 IgGs from patients with ALS (45\%-95\%) was significantly higher than IgGs from NCs $(30 \%-80 \%$ of the mean maximal binding). In the presence of high concentration of the antigen, the binding for anti-TDP-43 NAbs tended to be significant $(2 \mathrm{nM})$ or was on similar level $(20 \mathrm{nM})$ in both individuals with ALS and NC individuals. These data suggest that patients with ALS contain a significantly lower amount of highaffinity anti-TDP-43 NAbs in plasma compared with controls.
To evaluate the specificity of the binding of the anti-TDP43 plasma NAbs to TDP-43 antigen, we conducted control competition assays on the pooled plasma samples using antigens unrelated to ALS pathology. We performed competition ELISA assays using either tau monomers or $\alpha$-synuclein monomers in the fluid inhibition phase and plates coated with TDP-43 (figure 2, A and C), tau (figure $2 B$ ), or $\alpha$-synuclein (figure $2 D$ ). Neither the tau nor $\alpha$-synuclein monomers interfered with the binding of anti-TDP-43 plasma NAbs to plates coated with TDP-43 (figure 2, A and C) confirming no polyreactivity to other amyloidogenic antigens.

We then proceeded to check the apparent affinity profiles of anti- $\alpha$-synuclein and anti-tau plasma NAbs in pooled plasma samples from patients with ALS and NCs. The displacement curves for patients with ALS and NCs fitted a 2-affinity state model, with a substantial fraction (approximately 50\%) of the antibodies in the plasma samples characterized with high apparent affinity/avidity for both $\alpha$-synuclein and tau (figure 2, B and D). Similar displacement curves were observed for both groups, suggesting no differences in the avidity/affinity of either anti- $\alpha$-synuclein or anti-tau NAbs.

To verify that results were not a response of the difference in mean age between NCs and patients with ALS (table 1), a test comparing the maximal binding of anti-TDP-43 NAbs for elderly controls (age $>50$ years) to younger controls (aged $<50$ years) was performed. The test showed no significant differences in binding properties of anti-TDP-43 NAbs from plasma of controls stratified by age, at each TDP-43 concentration tested in the assay (figure 3 ). 
Figure 4 Relative Plasma TDP-43 and Immunocomplex Levels and Concentrations of Total Plasma TDP-43 and TDP-43 NAbs Complexes

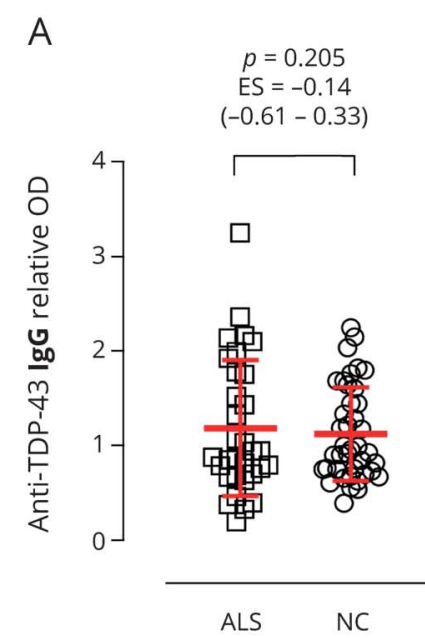

D
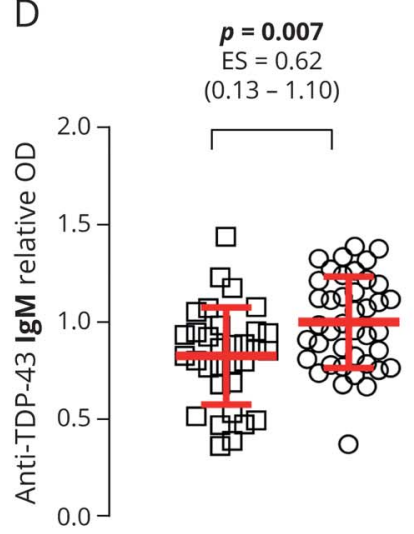

ALS NC

G

$$
\begin{gathered}
p=\mathbf{0 . 0 2 8} \\
\mathrm{ES}=-0.54 \\
(-1.02-0.05)
\end{gathered}
$$

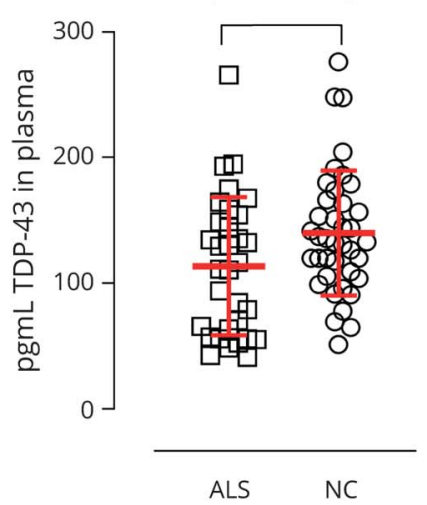

B

$$
\begin{gathered}
p=0.121 \\
\mathrm{ES}=0.32 \\
(-0.16-0.79)
\end{gathered}
$$

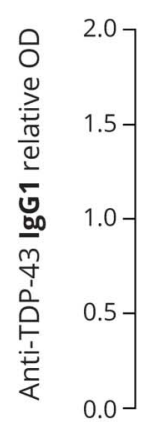

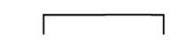

무임

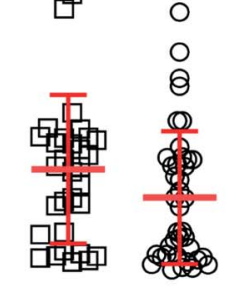

ALS NC

E

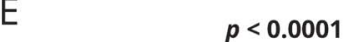

$\mathrm{ES}=-0.96$

$(-1.47--0.43)$

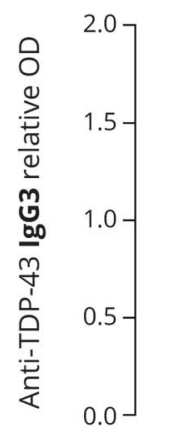

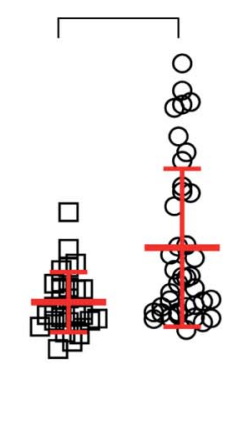

ALS NC

$\mathrm{H}$

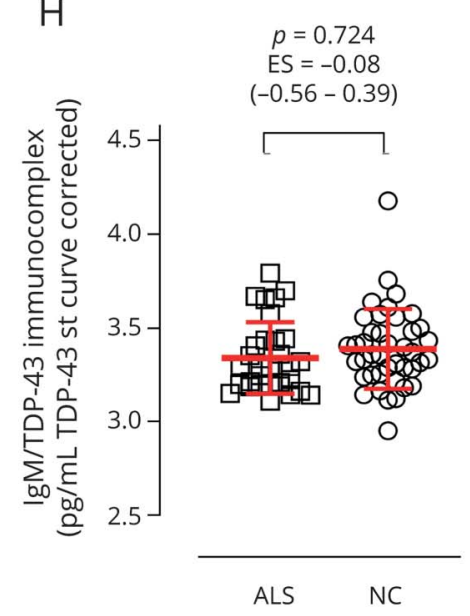

C

$p=0.695$

$\mathrm{ES}=-0.11$
$(-0.60-0.39)$

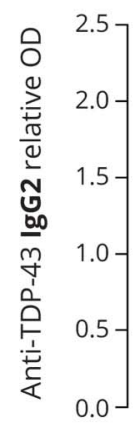
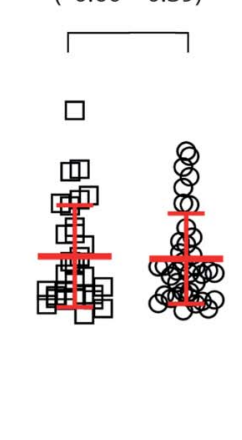

ALS NC

F

$p=0.005$
$\mathrm{ES}=0.70$
$(0.21-1.18)$

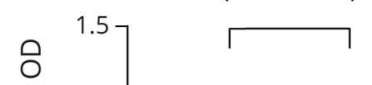

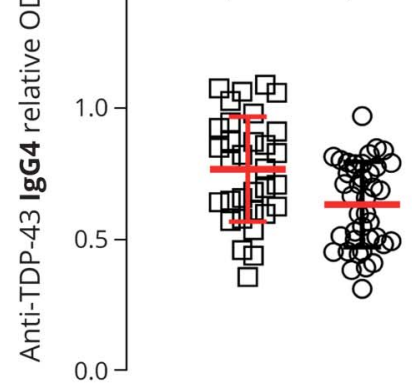

ALS NC

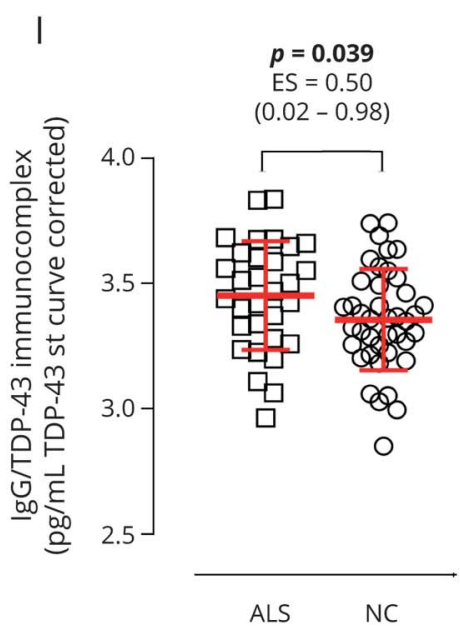

Distribution of relative anti-TDP-43 naturally occurring autoantibody plasma levels in patients with amyotrophic lateral sclerosis $(n=41)(A L S$, squares) and normal controls $(n=30)(N C s$, circles). ELISA relative optical densities (ODs) of anti-TDP-43 NAbs (A) total lgG, (B) IgG1, (C) IgG2, (D) IgM, (E) IgG3, and (F) IgG4. Total plasma TDP-43 concentration (G); TDP-43/lgM complexes (H) and TDP-43/lgG complexes (I) in plasma from patients with ALS ( $n=30)$ (squares) and NCs $(n=41)$ (circles). TDP-43 NAbs complex concentrations were quantified using TDP-43 standard curve. Dot plots show relative ODs with mean values (horizontal bars) $\pm \mathrm{SD}, \mathrm{ES}=$ Cohen effect size $(95 \% \mathrm{CI})$. Differences between groups were tested using the Student $t$ test or Mann-Whitney $U$ test. Ig = immunoglobulin; NAb = naturally occurring autoantibody; TDP-43 = 43-kDa TAR DNA-binding protein. 
Table 2 Global Plasma Immunoglobulin (Ig) Levels

\begin{tabular}{|c|c|c|c|c|c|}
\hline Global antibody levels, mg/dL & Patients with ALS $(n=30)$ & Normal controls $(n=41)$ & $p$ Value & ES & $95 \% \mathrm{Cl}$ \\
\hline IgG1 & 894.3 (648.9) [146.3-2,082.5] & 904.5 (478.9) [196.5-2,034] & 0.513 & -0.16 & -0.64 to 0.32 \\
\hline IgG2 & $604.1(468.1)[81.9-1,818.4]$ & $934.7(573.1)[215.8-2,328]$ & 0.108 & -0.52 & -1.10 to 0.08 \\
\hline IgG3 & 317.0 (198.4) [5.9-632.8] & $329.3(234.5)$ [25.6-904.1] & 0.817 & -0.06 & -0.53 to 0.42 \\
\hline IgG4 & $26.4(14.2)[3.7-69.9]$ & 20.97 (17.1) [0.9-58.9] & $0.045^{a}$ & 0.34 & -0.14 to 0.82 \\
\hline IgG total & $1,487(881.0)[14.9-3,430]$ & $1,910(1,045)[139.3-4,586]$ & 0.131 & -0.35 & -0.83 to 0.13 \\
\hline IgM & 318.7 (154.7) [7.1-704.9] & 497.9 (331.2) [12.8-1,352] & $0.035^{\mathrm{a}}$ & -0.65 & -1.16 to -0.12 \\
\hline
\end{tabular}

Abbreviations: ALS = amyotrophic lateral sclerosis; ES = Cohen effect size.

Results are presented as mean $( \pm S D)$ range [min-max].

a Significantly different.

Difference in Relative Levels of Anti-TDP-43 NAbs and Global Plasma Content of IgM, IgG1-4, and Total IgG Antibodies in Patients With ALS

Next, we investigated levels of total anti-TDP-43 IgG, IgG14, and IgM NAbs in plasma samples (figure 4, A-F). We observed significantly reduced relative levels of anti-TDP-43 IgM (figure 4D) and anti-TDP-43 IgG3 (figure 4E) and increased relative levels of anti-TDP-43 IgG4 (figure 4F) in ALS patient plasma samples compared with NCs. The relative levels of anti-TDP-43 total IgGs, IgG1, and IgG2 remained similar in both groups (figure $4, \mathrm{~A}-\mathrm{C}$, respectively).

Furthermore, we have observed significant differences between the patients with ALS and NCs for global levels of IgM and IgG4 immunoglobulins (table 2). Whereas IgM levels were decreased in patients with ALS, the IgG4 levels were increased. No differences in the levels of total IgG and subclass IgG1-3 were observed between ALS and NCs.

\section{Increased Levels of Plasma Anti-TDP-43 and NAbs/TDP-43 Complexes in Patients With ALS}

We also measured the concentration of plasma TDP-43 protein, IgM/TDP-43, and IgG/TDP-43 complexes (figure 4, G-I). The mean $( \pm S D)$ plasma concentration of TDP-43 was slightly higher in the NC group $(139.8 \pm 8 \mathrm{pg} / \mathrm{mL})$ than in patients with ALS $(113.3 \pm 9.7 \mathrm{pg} / \mathrm{mL}$ ) (figure $4 \mathrm{G})$. Furthermore, the results also show a significant increase in $\operatorname{IgG}$ / TDP-43 complex concentrations in patients with ALS (figure 4I) vs NCs, whereas IgM/TDP-43 complex concentrations did not differ between the groups (figure $4 \mathrm{H}$ ).

\section{Anti-TDP-43 NAb Affinity and Levels Correlate With Clinical Measures}

For $40 \mathrm{nM}, 8 \mathrm{nM}$, and $1.6 \mathrm{nM}$ of free TDP-43 monomer, the percent of maximal binding obtained for anti-TDP-43 NAbs in ALS plasma samples at the sampling time (average of 1.2 years after onset) could predict the disease duration (average 3.4 years after onset) (figure 5A). However, the percent of maximal binding did not correlate with ALS-FRS-R score (figure 5B). It is worth noticing that the $p$ values were most significant with high affinity/avidity plasma fraction, which is indicated by efficient inhibition of antibody binding in the presence of low (1-10 nM) concentrations of TDP-43. These data indicate that patients with a significantly lower proportion of high-affinity anti-TDP-43 NAbs in plasma had a shorter total disease duration hence more rapid progressing disease. This is in contrast to the patients with a higher proportion of high-affinity anti-TDP-43 NAbs at the disease onset.

Furthermore, anti-TDP-43 IgM levels in plasma from patients with ALS withdrawn at the sampling time (average of 1.2 years after onset) correlated with longer disease duration (predicted longer disease duration) (average 3.4 years after onset) (figure 5C). Contrary, levels of anti-TDP-43 IgG4 correlated with shorter disease duration (predicted shorter disease duration) (figure 5C). These results indicate that patients with relatively high levels of anti-TDP-43 IgM and low levels of anti-TDP-43 IgG4 at the disease onset or shortly after had a relatively long survival time hence slower disease progression. ALS-FRS-R did not correlate with anti-TDP-43 $\mathrm{NAb}$ levels (figure 5D).

The global Ig plasma content of IgG total, IgG1-4, and IgM did not correlate with any of the clinical measures (data not shown). Ten patients with ALS included in the study cohort had had comorbid conditions; thus, we have analyzed whether these could influence the interpretation of our results. The mean of total disease duration for patients with comorbidities was 2.9 years and was not significantly different $(p=0.28)$ from patients with no comorbid conditions ( 3.5 years). The affinity/avidity of anti-TDP-43 NAbs expressed as \% of max binding, the levels of anti-TDP-43 antibodies, and global antibody levels did not differ between the patient groups (data not shown).

\section{Discussion}

Here, we report disturbances in relative binding properties and in the relative levels of NAbs specific for the pathogenic protein, TDP-43, in plasma samples from patients with ALS. 
A. Affinity vs. disease duration

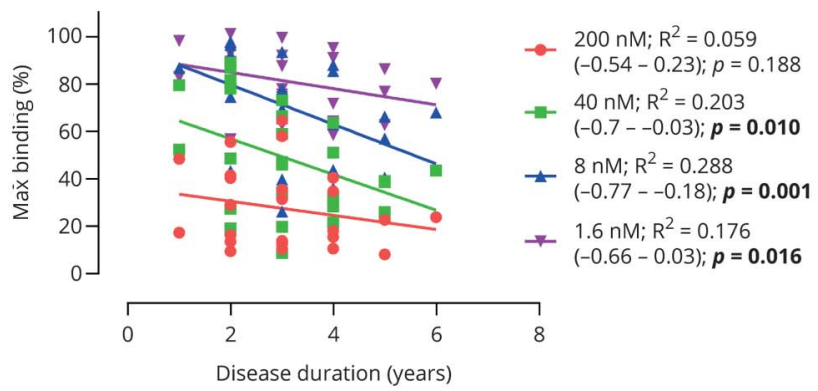

C. TDP-43 NAbs level vs. disease duration

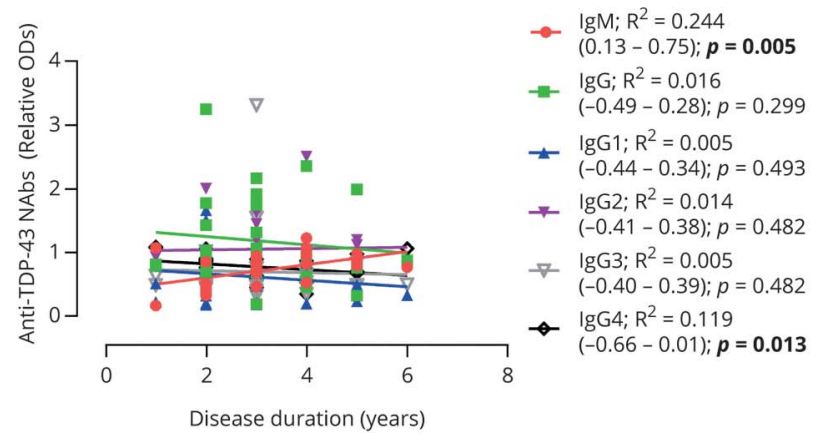

B. Affinity vs. ALS-FRS-R

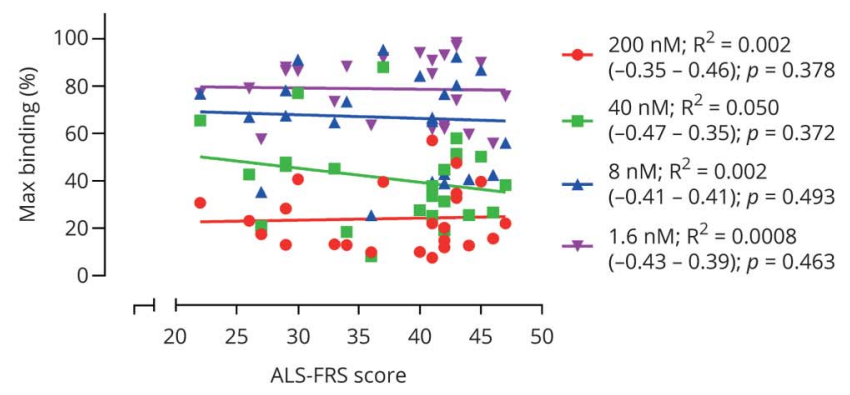

D. TDP-43 NAbs level vs. ALS-FRS-R

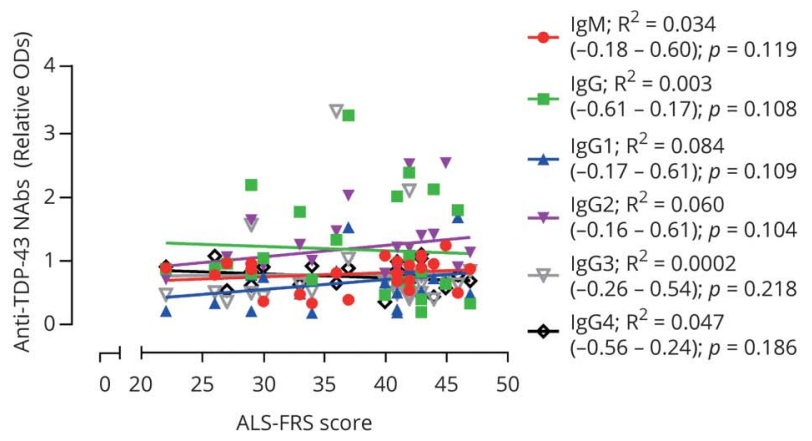

(A) Correlation of disease duration and (B) ALS-FRS-R score with the affinity/avidity of anti-TDP-43 NAbs (expressed as \% of max binding of anti-TDP-43 NAbs to immobilized TDP-43 monomer $(1 \mu \mathrm{g} / \mathrm{mL})$ in competitive ELISA assay in the presence of free 200, 40, 8, and $1.6 \mathrm{nM}$ TDP-43). (C) Correlation of disease duration and (D) ALS-FRS-R score with the relative optical densities (ODs) of anti-TDP-43 total IgG, IgG1-4 subclass, and IgM NAbs. Correlation analyses were performed using the Spearman rank correlation test $(\rho)(95 \% \mathrm{Cl})$. ALS-FRS-R = Amyotrophic Lateral Sclerosis Functional Rating Scale-Revised; Ig = immunoglobulin; NAb = naturally occurring autoantibody; TDP-43 = 43-kDa TAR DNA-binding protein.

First, we showed that plasma samples from NCs contain approximately equal low- and high-affinity/avidity binding components, whereas in plasma from patients with ALS, we observed a significantly decreased fraction of high affinity/ avidity anti-TDP-43 NAbs.

Alterations in NAbs toward specific pathogenic proteins such as $\alpha$-synuclein, amyloid $\beta$, and tau have previously been reported in relation to 2 of the most common neurodegenerative disorders, namely Parkinson disease and Alzheimer disease. ${ }^{25-28}$ We have recently shown a reduction in apparent high-affinity/avidity anti- $\alpha$-synuclein NAbs in Parkinson disease and multiple system atrophy, ${ }^{24}$ both disorders characterized by abnormal aggregation of this protein in neurons and glial cells, respectively.

It is remarkable that the apparent levels of high-affinity/ avidity anti-TDP-43 NAbs at the disease onset or shortly after correlated with the subsequent disease duration. More specifically, our data indicate that patients with a significantly lower proportion of high-affinity anti-TDP-43 NAbs in plasma at the withdrawal time point, had a shorter survival time. This suggests that NAb affinity/avidity may be a predictor of and/or contributor to disease progression.
As TDP-43 species are present in body fluids, inclusive blood and $\mathrm{CSF}^{9}{ }^{9}$ NAbs are probably important for maintaining protein homeostasis through antibody-mediated clearance mechanism. ${ }^{29}$ In addition to neurodegenerative changes in the CNS, muscle and nerves appear to be the site of immunologic activation in ALS. ${ }^{21}$ Also, axial skeletal muscles can be an additional site of TDP-43 pathology in patients with ALS, including sporadic and familial cases. ${ }^{30}$ Of interest, TDP-43 is an essential protein for normal skeletal muscle formation, and it is able to spontaneously form cytoplasmic, amyloid-like oligomeric assemblies, the so called myo-granules, during regeneration of skeletal muscles. ${ }^{31}$ Furthermore, these myogranules can seed amyloid-like fibrils in vitro, which suggests a link between the normal biological functions of TDP-43 and pathologic TDP-43 aggregates. Therefore, impaired peripheral clearance of misfolded proteins may play an important role in TDP-43 pathology in ALS.

Second, patients with ALS with relatively low numbers of anti-TDP-43 IgMs and relatively high levels of anti-TDP-43 IgG4 presented much faster disease progression than those with high levels of anti-TDP-43 IgM and low levels of antiTDP-43 IgG4. Alterations in NAb plasma levels may reflect progress of the neurodegeneration, and thus, they might be 
useful as diagnostic and prognostic biomarkers in early diagnosis. $^{32,33}$

IgMs and IgG3 represent an early response to the pathogen by activating complement system to ensure quick immune response. ${ }^{34}$ A decrease in IgM and IgG3 anti-TDP-43 NAbs might therefore suggest impaired clearance mechanism through phagocytosis. IgG4s on the other hand are weak inducers of effector cells, cannot activate the complement cascade, and are known to be involved in mediating chronic responses. $^{35,36}$ Beekeepers, animal laboratory workers, and individuals undergoing allergen immunotherapy possess high serum levels of allergen-specific IgG4, which exhibit immunosuppressive functions, protecting the individual from anaphylactic reactions. ${ }^{37,38}$ In autoimmune/immune-mediated diseases, such as pemphigus vulgaris, pemphigus foliaceus, and MuSK myasthenia gravis, IgG4 autoantibodies are pathogenic. $^{39}$ IgG4-related diseases are normally treated with corticosteroids ${ }^{40}$; however, patients with ALS do not respond to this kind of treatment. This may suggest that the observed increase of IgG4 in ALS does not have an inflammatory origin but rather is of immunosuppressive/protective character. Whether this could be a consequence of prolonged exposure to subclinical levels of pathogenic TDP-43 and the acquisition of an immune intolerance over time toward aggregated TDP43 in patients with ALS should be further investigated.

Importantly, we did not detect an overall difference in total anti-TDP-43 IgG levels and global levels of IgGs, IgG1-3. However, patients with ALS presented decreased global levels of IgMs and increased global levels of IgG4. These overall IgM antibody decline may reflect systemic immunologic alterations in ALS and could indicate a decreased homeostatic capability or selective immunodeficiency in ALS, perhaps reflecting its progressive course. Similar results were observed for multiple system atrophy, a fast progressing neurodegenerative disease. ${ }^{41}$ IgG4 is usually the least-represented IgG subclass in human serum; however, as mentioned before, high IgG4 levels can occur in particular conditions, usually following repeated or chronic exposure to an antigen. Elevated levels of IgG4 are also associated with inflammation in a range of chronic pathologic conditions, such as rheumatoid arthritis. ${ }^{42}$ Thus, the main function of IgG4 is probably to interfere with immune inflammation induced by complement-fixing antibodies. ${ }^{43}$ Nonspecific changes in antibodies were also investigated before in patients with ALS, but the results were conflicting. ${ }^{44-49}$

Under normal physiologic conditions, a significant proportion of the NAbs have their active site blocked by the high amount of available self-antigens. ${ }^{12}$ On binding to self-antigens, NAbs form immune complexes, which are subsequently eliminated from the circulation, primarily by phagocytosis. ${ }^{50} \mathrm{We}$ have measured the IgM/TDP-43 and total IgG/TDP-43 immunocomplex levels in plasma and found no difference between patients with ALS and NCs. The immune complexes were at very low concentrations in plasma, which may partially explain the results. Moreover, the anti-TDP-43 plasma NAbs, polyclonal in nature, may be directly occupied by oligomeric or fibrillar forms of TDP-43, which are probably not detected by the capture antibody in our assay. Some studies have shown an increase in circulating immune complexes in sera of patients with ALS compared with controls. $44,46,48,51,52$

NAbs may represent an important physiologic mechanism inhibiting peptide/protein fibrillation and exhibiting rescuing effects on microglial uptake, further defining clinical manifestations in ALS. A dysfunction in this recognition pattern by dysfunctional B-cell maturation, immune shifts, or antigenspecific reduced $B$ cells may explain both the observed aberrant $\mathrm{NAb}$ production and reduced antibody binding properties in patients with ALS. The blueprints from these NAbs are inscribed in the sequence of the B-cell receptors on a distinct B-cell subset, called B1 cells. ${ }^{53,54}$ Supported by our correlation analyses, at this point, we can only speculate that the anti-TDP-43 IgM producing B1-cell population may already be reduced or impaired in the prodromal phase of ALS, resulting in an overload of TDP-43 protein. This situation could result in a greater pressure on the clearance mechanisms. Thus, after the primary recognition of toxic TDP-43 species, the antibody isotype switches to an IgG-dominated response characterized, in this case, by lower-affinity/avidity antibodies, as supported by present results. Further longitudinal, in-depth characterization of the adaptive immune system components of patients with ALS with focus on humoral immune responses can give us insights into disease pathogenesis.

ALS progression is characterized by loss of physical function in various domains, i.e., the bulbar, fine and gross motor, and respiratory domain. The ALS-FRS-R scale uses precisely this loss of function as a marker for disease severity and disease progression. ${ }^{55,56}$ Based on our result, we can speculate that the antibody status is not directly correlated with the loss of physical function, but rather with the disease duration. We must bear in mind that this study was not longitudinal, and the majority of samples were collected as early as 1 year from disease onset with relatively mild to moderate stage of disease (ALS-FRS-R scores of median 41). At this stage, the affinity/ avidity and the levels of anti-TDP-43 NAbs may simply not yet be reflected in loss of physical functions, which may partially explain why our immune measures do not correlate with the ALS-FRS-R outcomes. Earlier, comprehensive, longitudinal studies on the immune status of patients with ALS have reported positive correlation of total leukocyte and neutrophil numbers with disease progression; however, numbers of $\mathrm{CD}^{+} \mathrm{T}$ cells correlated negatively with ALS-FRS-R decline. ${ }^{57,58}$ Of interest, there was no correlation with total B-cell numbers. ${ }^{58}$ It is a well-known fact that antibody responses to protein antigens require help from antigen-specific $\mathrm{CD}^{+}{ }^{+} \mathrm{T}$ cells. ${ }^{59}$ It is a bidirectional relationship and an aberration of one component may be reflected in the function of another one, hence our results. It has also been suggested that $\mathrm{CD}^{+} \mathrm{T}$ cells may exhibit neuroprotective function in ALS. 
This was evidenced by the reduced number and suppressive abilities of $\mathrm{T}$ regulatory cells, ${ }^{49,60}$ which are negatively correlated with ALS-FRS-R ${ }^{61,62}$ Other studies have found increased numbers of $\mathrm{CD}^{+} \mathrm{T}$ helper cells without changes in $\mathrm{CD} 8^{+}$cells, monocytes, and macrophages. ${ }^{63}$ Taken together, these and our findings may indicate the critical involvement of peripheral immune deficits in ALS pathology.

There are some limitations in the study, which should be taken under consideration. The size of the sample is small, and the biological and clinical variations between the individuals are large. However, the differences found were highly significant despite the small sample size. The NCs were younger than patients with ALS; however, there was no significant difference in binding affinity/avidity properties of TDP-43 NAbs from plasma of controls stratified by age. Longitudinal studies in patients with ALS could reveal the effects of disease progression on the regulatory immune system. Also, studies in the prodromal phase of ALS could reveal if the observed immune deficiency is already seen before the disease onset. At the present time, we can only hypothesize that a reduction in high affinity NAbs impairs the clearance process and thus mounts the mechanism behind the aggregations of pathologic proteins in ALS.

In conclusion, we observed a decline in TDP-43 reactivity in patients with ALS. The apparent decrease in levels of highaffinity/avidity anti-TDP-43 NAbs correlates with and thereby predicts disease severity. The decline in high-affinity anti-TDP-43 NAbs might impair the capacity to block and neutralize toxic proteins, and although this requires further investigations, data from this study provide rationale for immunotherapy against aggregated TDP-43 as a promising strategy to slow progression of sporadic ALS.

\section{Acknowledgment}

The authors thank all participants and patients for their cooperation. Furthermore, they extend special thanks to the Neurological Department at Bispebjerg-Frederiksberg Hospital, Copenhagen, Denmark. The authors acknowledge Pernille Roed Christensen, research nurse at the department for her great help with the recruitment and patient follow-up, data, and sample collection. The authors also thank Lis Arneberg, MSc, for her excellent technical assistance in optimizing the competitive ELISA assay.

\section{Study Funding}

This study was funded by the Aage og Johanne Louis-Hansens Foundation, Toyota-Fonden, Dagmar Marshalls Fond, and Civilingeniør Frode V Nyegaard og Hustrus Fond.

\section{Disclosure}

The authors report no disclosures. Go to Neurology.org/NN for full disclosures.

\section{Publication History}

Received by Neurology: Neuroimmunology \& Neuroinflammation May 15, 2020. Accepted in final form November 16, 2020.

\section{Appendix Authors}

\begin{tabular}{lll}
\hline Name & Location & Contribution \\
\hline $\begin{array}{lll}\text { Anne } \\
\text { Kallehauge }\end{array}$ & $\begin{array}{l}\text { Research Laboratory for } \\
\text { Nielsen, MSc }\end{array}$ & $\begin{array}{l}\text { Designed and } \\
\text { Cereology and }\end{array}$ \\
& $\begin{array}{l}\text { Neuroscience, Bispebjerg- } \\
\text { Frederiksberg Hospital, } \\
\text { Copenhagen, Denmark }\end{array}$ & $\begin{array}{l}\text { major role in the } \\
\text { acquisition of data; } \\
\text { analyzed the data; and } \\
\text { drafted the manuscript for } \\
\text { intellectual content }\end{array}$ \\
& & \\
\end{tabular}

\begin{tabular}{|c|c|c|}
\hline $\begin{array}{l}\text { Jonas Folke, } \\
\text { PhD }\end{array}$ & $\begin{array}{l}\text { Research Laboratory for } \\
\text { Stereology and } \\
\text { Neuroscience, Bispebjerg- } \\
\text { Frederiksberg Hospital, } \\
\text { Copenhagen, Denmark }\end{array}$ & $\begin{array}{l}\text { Major role in the } \\
\text { acquisition of data; } \\
\text { analyzed the data; and } \\
\text { revised the manuscript for } \\
\text { intellectual content }\end{array}$ \\
\hline $\begin{array}{l}\text { Sylwia } \\
\text { Owczarek, } \\
\text { PhD }\end{array}$ & $\begin{array}{l}\text { Research Laboratory for } \\
\text { Stereology and } \\
\text { Neuroscience, Bispebjerg- } \\
\text { Frederiksberg Hospital, } \\
\text { Copenhagen, Denmark }\end{array}$ & $\begin{array}{l}\text { Important role in the } \\
\text { acquisition of data; } \\
\text { analyzed the data; and } \\
\text { revised the manuscript for } \\
\text { intellectual content }\end{array}$ \\
\hline
\end{tabular}

\begin{tabular}{|c|c|c|}
\hline $\begin{array}{l}\text { Kirsten } \\
\text { Svenstrup, } \\
\text { MD, PhD }\end{array}$ & $\begin{array}{l}\text { Department of Neurology, } \\
\text { Bispebjerg-Frederiksberg } \\
\text { Hospital, Copenhagen, } \\
\text { Denmark; Neuromuscular } \\
\text { Clinic, Department of } \\
\text { Neurology, Rigshospitalet, } \\
\text { Copenhagen, Denmark }\end{array}$ & $\begin{array}{l}\text { Major role in the patient } \\
\text { enrollment and acquisition } \\
\text { of samples and data; } \\
\text { analyzed the data; and } \\
\text { revised the manuscript for } \\
\text { intellectual content }\end{array}$ \\
\hline $\begin{array}{l}\text { Kristian } \\
\text { Winge, MD, } \\
\text { PhD }\end{array}$ & $\begin{array}{l}\text { Department of Neurology, } \\
\text { Bispebjerg-Frederiksberg } \\
\text { Hospital, University } \\
\text { Hospital of Copenhagen, } \\
\text { Denmark }\end{array}$ & $\begin{array}{l}\text { Major role in the patient } \\
\text { enrollment and acquisition } \\
\text { of samples and revised the } \\
\text { manuscript for intellectual } \\
\text { content }\end{array}$ \\
\hline $\begin{array}{l}\text { Bente } \\
\text { Pakkenberg, } \\
\text { MD, DMSc }\end{array}$ & $\begin{array}{l}\text { Research Laboratory for } \\
\text { Stereology and } \\
\text { Neuroscience, Bispebjerg- } \\
\text { Frederiksberg Hospital, } \\
\text { Copenhagen, Denmark; } \\
\text { Institute of Clinical } \\
\text { Medicine, Faculty of Health } \\
\text { and Medical Sciences, } \\
\text { University of Copenhagen, } \\
\text { Denmark }\end{array}$ & $\begin{array}{l}\text { Interpreted the data and } \\
\text { drafting a significant } \\
\text { portion of the manuscript }\end{array}$ \\
\hline
\end{tabular}

\begin{tabular}{|c|c|c|}
\hline $\begin{array}{l}\text { Susana } \\
\text { Aznar, PhD }\end{array}$ & $\begin{array}{l}\text { Research Laboratory for } \\
\text { Stereology and } \\
\text { Neuroscience, Bispebjerg- } \\
\text { Frederiksberg Hospital, } \\
\text { Copenhagen, Denmark; } \\
\text { Copenhagen Center for } \\
\text { Translational Research, } \\
\text { Copenhagen University } \\
\text { Hospital, Bispebjerg and } \\
\text { Frederiksberg, Denmark }\end{array}$ & $\begin{array}{l}\text { Interpreted the data and } \\
\text { drafting a significant } \\
\text { portion of the manuscript }\end{array}$ \\
\hline $\begin{array}{l}\text { Tomasz } \\
\text { Brudek, PhD }\end{array}$ & $\begin{array}{l}\text { Research Laboratory for } \\
\text { Stereology and } \\
\text { Neuroscience, Bispebjerg- } \\
\text { Frederiksberg Hospital, } \\
\text { Copenhagen, Denmark; } \\
\text { Copenhagen Center for } \\
\text { Translational Research, } \\
\text { Copenhagen University } \\
\text { Hospital, Bispebjerg and } \\
\text { Frederiksberg, Denmark }\end{array}$ & $\begin{array}{l}\text { Designed and } \\
\text { conceptualized the study; } \\
\text { analyzed the data; and } \\
\text { drafted the manuscript for } \\
\text { intellectual content }\end{array}$ \\
\hline
\end{tabular}


3. Nishihira Y, Tan CF, Onodera O, et al. Sporadic amyotrophic lateral sclerosis: two pathological patterns shown by analysis of distribution of TDP-43-immunoreactive neuronal and glial cytoplasmic inclusions. Acta Neuropathol 2008;116:169.

4. Geser F, Lee V, Trojanowski JQ. Amyotrophic lateral sclerosis and frontotemporal lobar degeneration: a spectrum of TDP-43 proteinopathies. Neuropathology 2010; 30:103-112.

5. Neumann M, Kwong LK, Lee EB, et al. Phosphorylation of S409/410 of TDP-43 is a consistent feature in all sporadic and familial forms of TDP-43 proteinopathies. Acta Neuropathol 2009;117:137-149.

6. Baloh RH. TDP-43: the relationship between protein aggregation and neurodegeneration in amyotrophic lateral sclerosis and frontotemporal lobar degeneration. FEBS J 2011;278:3539-3549.

7. Mackenzie IRA, Bigio EH, Ince PG, et al. Pathological TDP-43 distinguishes sporadic amyotrophic lateral sclerosis from amyotrophic lateral sclerosis with SOD1 mutations. Ann Neurol 2007;61:427-434.

8. Neumann M, Sampathu DM, Kwong LK, et al. Ubiquitinated TDP-43 in frontotemporal lobar degeneration and amyotrophic lateral sclerosis. Science 2006;314: $130-133$.

9. Feneberg E, Gray E, Ansorge O, Talbot K, Turner MR. Towards a TDP-43-based biomarker for ALS and FTLD. Mol Neurobiol 2018;55:7789-7801.

10. Ishii T, Kawakami E, Endo K, Misawa H, Watabe K. Formation and spreading of TDP-43 aggregates in cultured neuronal and glial cells demonstrated by time-lapse imaging. PLoS One 2017;12:e0179375.

11. Iguchi $Y$, Eid L, Parent M, et al. Exosome secretion is a key pathway for clearance of pathological TDP-43. Brain 2016;139:3187-3201.

12. Avrameas S, Alexopoulos H, Moutsopoulos HM. Natural autoantibodies: an undersugn hero of the immune system and autoimmune disorders-a point of view. Front Immunol 2018;9:1320.

13. Nagele EP, Han M, Acharya NK, DeMarshall C, Kosciuk MC, Nagele RG. Natural IgG autoantibodies are abundant and ubiquitous in human sera, and their number is influenced by age, gender, and disease. PLoS One 2013;8:e60726.

14. Lutz HU. Homeostatic roles of naturally occurring antibodies: an overview. J Autoimmun 2007;29:287-294.

15. Neff F, Wei X, Nölker C, Bacher M, Du Y, Dodel R. Immunotherapy and naturally occurring autoantibodies in neurodegenerative disorders. Autoimmun Rev 2008;7: 501-507.

16. Dodel R, Balakrishnan K, Keyvani K, et al. Naturally occurring autoantibodies against $\beta$-amyloid: investigating their role in transgenic animal and in vitro models of Alzheimer's disease. J Neurosci 2011;31:5847-5854.

17. Wootla B, Watzlawik JO, Warrington AE. Naturally occurring monoclonal antibodies and their therapeutic potential for neurologic diseases. JAMA Neurol 2015;72; 1346-1353.

18. Nimmerjahn F, Ravetch JV. Anti-inflammatory actions of intravenous immunoglobulin. Annu Rev Immunol 2008;26:513-533.

19. Maddur MS, Kaveri SV, Bayry J. Circulating normal IgG as stimulator of regulatory T cells: lessons from intravenous immunoglobulin. Trends Immunol 2017;38: 789-792.

20. Strait RT, Posgai MT, Mahler A, et al. IgG1 protects against renal disease in a mouse model of cryoglobulinaemia. Nature 2015;517:501.

21. Malaspina A, Puentes F, Amor S. Disease origin and progression in amyotrophic lateral sclerosis: an immunology perspective. Int Immunol 2015;27:117-129.

22. Brooks BR, Miller RG, Swash M, Munsat TL; World Federation of Neurology Research Group on Motor Neuron Diseases. El Escorial revisited: revised criteria for the diagnosis of amyotrophic lateral sclerosis. Amyotroph Lateral Scler Other Motor Neuron Disord 2009; 1:293-299.

23. Sawilowsky SS. New effect size rules of thumb. J Mod Appl Stat Methods 2009;8: 597-599.

24. Brudek T, Winge K, Folke J, et al. Autoimmune antibody decline in Parkinson's disease and Multiple System Atrophy; a step towards immunotherapeutic strategies. Mol Neurodegener 2017;12:44

25. Scott KM, Kouli A, Yeoh SL, Clatworthy MR, Williams-Gray CH. A rystematic review and meta-analysis of alpha synuclein auto-antibodies in Parkinson's disease. Front Neurol 2018;9:815.

26. Dorothee G, Bottlaender M, Moukari E. Distinct patterns of antiamyloid-beta antibodies in typical and atypical Alzheimer disease. Arch Neurol 2012;69;1181-1185.

27. Bartos A, Fialová L, Švarcová J. Lower serum antibodies against tau protein and heavy neurofilament in Alzheimer's disease. J Alzheimers Dis 2018;64:751-760.

28. Wu J, Li L. Autoantibodies in Alzheimer's disease: potential biomarkers, pathogenic roles, and therapeutic implications. J Biomed Res 2016;30:361-372

29. Maddur MS, Lacroix-Desmazes S, Dimitrov JD, Kazatchkine MD, Bayry J, Kaveri SV. Natural antibodies: from first-line defense against pathogens to perpetual immune homeostasis. Clin Rev Allergy Immunol 2020;58:213-228.

30. Cykowski MD, Powell SZ, Appel JW, Arumanayagam AS, Rivera AL, Appel SH. Phosphorylated TDP-43 (pTDP-43) aggregates in the axial skeletal muscle of patients with sporadic and familial amyotrophic lateral sclerosis. Acta Neuropathologica Commun 2018;6:28.

31. Vogler TO, Wheeler JR, Nguyen ED, et al. TDP-43 and RNA form amyloid-like myogranules in regenerating muscle. Nature 2018;563:508-513.

32. Han M, Nagele E, DeMarshall C, Acharya N, Nagele R. Diagnosis of Parkinson's disease based on disease-specific autoantibody profiles in human sera. PLoS One 2012;7:e32383.
33. Nagele E, Han M, DeMarshall C, Belinka B, Nagele R. Diagnosis of Alzheimer's disease based on disease-specific autoantibody profiles in human sera. PLoS One 2011;6:e23112.

34. Collins AM, Jackson KJL. A temporal model of human IgE and IgG antibody function. Front Immunol 2013;4:235

35. Aalberse RC, Stapel SO, Schuurman J, Rispens T. Immunoglobulin G4: an odd antibody. Clin Exp Allergy 2009;39:469-477.

36. Vidarsson G, Dekkers G, Rispens T. IgG subclasses and allotypes: from structure to effector functions. Front Immunol 2014;5:520.

37. Meiler F, Klunker S, Zimmermann M, Akdis CA, Akdis M. Distinct regulation of IgE, IgG4 and IgA by $\mathrm{T}$ regulatory cells and toll-like receptors. Allergy 2008;63: $1455-1463$

38. van de Veen W, Akdis M. Role of IgG4 in IgE-mediated allergic responses. J Allergy Clin Immunol 2016;138:1434-1435.

39. Trampert DC, Hubers LM, van de Graaf SFJ, Beuers U. On the role of IgG4 in inflammatory conditions: lessons for IgG4-related disease. Biochim Biophys Acta Mol Basis Dis 2018;1864:1401-1409.

40. Khosroshahi A, Wallace ZS, Crowe JL, et al. International consensus guidance statement on the management and treatment of IgG4-related disease. Arthritis Rheumatol 2015;67:1688-1699.

41. Folke J, Rydbirk R, Løkkegaard A, et al. Distinct autoimmune anti- $\alpha$-synuclein antibody patterns in Multiple System Atrophy and Parkinson's disease. Front Immunol 2019;10:2253

42. Chen LF, Mo YQ, Ma JD, Luo L, Zheng D, Dai L. Elevated serum IgG4 defines specific clinical phenotype of rheumatoid arthritis. Mediators Inflamm 2014;2014 $1-10$.

43. Crescioli S, Correa I, Karagiannis P, et al. IgG4 characteristics and functions in cancer immunity. Curr Allergy Asthma Rep 2016;16:7.

44. Saleh IA, Zesiewicz T, Xie Y, et al. Evaluation of humoral immune response in adaptive immunity in ALS patients during disease progression. J Neuroimmuno 2009;215:96-101.

45. Provinciali L, Laurenzi MA, Vesprini L, et al. Immunity assessment in the early stages of amyotrophic lateral sclerosis: a study of virus antibodies and lymphocyte subsets. Acta Neurol Scand 1988;78:449-454.

46. Apostolski S, Nikolić J, Bugarski-Prokopljević C, Miletić V, Pavlović S, Filipović S. Serum and CSF immunological findings in ALS. Acta Neurol Scand 1991;83:96-98.

47. Chen X, Feng W, Huang R, et al. Evidence for peripheral immune activation in amyotrophic lateral sclerosis. J Neurol Sci 2014;347:90-95.

48. Bartfeld H, Dham C, Donnenfeld $\mathrm{H}$, et al. Immunological profile of amyotrophic lateral sclerosis patients and their cell-mediated immune responses to viral and CNS antigens. Clin Exp Immunol 1982;48:137-146.

49. Rentzos M, Evangelopoulos E, Sereti E, et al. Alterations of T cell subsets in ALS: a systemic immune activation? T cell subsets in ALS. Acta Neurol Scand 2011;125 260-264.

50. Chen Y, Park YB, Patel E, Silverman GJ. IgM antibodies to apoptosis-associated determinants recruit $\mathrm{C} 1 \mathrm{q}$ and enhance dendritic cell phagocytosis of apoptotic cells J Immunol 2009;182:6031-6043.

51. Tachovsky TG, Koprowski H, Lisak RP, Theofilopoulos AN, Dixon FJ. Circulating immune complexes in multiple sclerosis and other neurological diseases. Lancet 1976 308:997-999.

52. Noronha ABC, Antel JP, Roos RP, Medof ME. Circulating immune complexes in neurologic disease. Neurology 1981;31:1402.

53. Grasseau A, Boudigou M, Pottier LL, et al. Innate B cells: the archetype of protective immune cells. Clin Rev Allergy Immunol 2019;58:92-106.

54. Lobo PI. Role of natural autoantibodies and natural IgM anti-leucocyte autoantibodies in health and disease. Front Immunol 2016;7:198.

55. Cedarbaum JM, Stambler N, Malta E, et al. The ALSFRS-R: a revised ALS functional rating scale that incorporates assessments of respiratory function. J Neurol Sci 1999; 169:13-21.

56. Bakker LA, Schröder CD, Es van MA, Westers P, Visser-Meily JMA, Berg van den LH. Assessment of the factorial validity and reliability of the ALSFRS-R: a revision of its measurement model. J Neurol 2017;264:1413-1420.

57. Murdock BJ, Zhou T, Kashlan SR, Little RJ, Goutman SA, Feldman EL. Correlation of peripheral immunity with rapid amyotrophic lateral sclerosis progression. JAMA Neurol 2017;74:1446-154.

58. Gustafson MP, Staff NP, Bornschlegl S, et al. Comprehensive immune profiling reveals substantial immune system alterations in a subset of patients with amyotrophic lateral sclerosis. PLoS One 2017;12:e0182002.

59. Petersone L, Edner NM, Ovcinnikovs V, et al. T cell/B cell collaboration and autoimmunity: an intimate relationship. Front Immunol 2018;9:1941.

60. Mantovani S, Garbelli S, Pasini A, et al. Immune system alterations in sporadic amyotrophic lateral sclerosis patients suggest an ongoing neuroinflammatory process. J Neuroimmunol 2009;210:73-79.

61. Henkel JS, Beers DR, Wen S, et al. Regulatory T-lymphocytes mediate amyotrophic lateral sclerosis progression and survival. EMBO Mol Med 2013;5:64-79.

62. Beers DR, Zhao W, Wang J, et al. ALS patients' regulatory T lymphocytes are dysfunctional, and correlate with disease progression rate and severity. JCI Insight 2017; 2:e89530

63. Zhang R, Gascon R, Miller RG, et al. Evidence for systemic immune system alterations in sporadic amyotrophic lateral sclerosis (sALS). J Neuroimmunol 2005;159: 215-224. 


\section{Neurology \\ Neuroimmunology \& Neuroinflammation}

TDP-43-specific Autoantibody Decline in Patients With Amyotrophic Lateral Sclerosis

Anne Kallehauge Nielsen, Jonas Folke, Sylwia Owczarek, et al.

Neurol Neuroimmunol Neuroinflamm 2021;8;

DOI 10.1212/NXI.0000000000000937

This information is current as of December 24, 2020

\section{Updated Information \& Services}

References

Subspecialty Collections

Permissions \& Licensing

\section{Reprints}

including high resolution figures, can be found at:

http://nn.neurology.org/content/8/2/e937.full.html

This article cites 63 articles, 4 of which you can access for free at: http://nn.neurology.org/content/8/2/e937.full.html\#\#ref-list-1

This article, along with others on similar topics, appears in the following collection(s):

All Immunology

http://nn.neurology.org//cgi/collection/all_immunology

Amyotrophic lateral sclerosis

http://nn.neurology.org//cgi/collection/amyotrophic_lateral_sclerosis_

Information about reproducing this article in parts (figures,tables) or in its entirety can be found online at:

http://nn.neurology.org/misc/about.xhtml\#permissions

Information about ordering reprints can be found online:

http://nn.neurology.org/misc/addir.xhtml\#reprintsus

Neurol Neuroimmunol Neuroinflamm is an official journal of the American Academy of Neurology.

Published since April 2014, it is an open-access, online-only, continuous publication journal. Copyright

Copyright $\left({ }^{\circ} 2020\right.$ The Author(s). Published by Wolters Kluwer Health, Inc. on behalf of the American

Academy of Neurology.. All rights reserved. Online ISSN: 2332-7812.

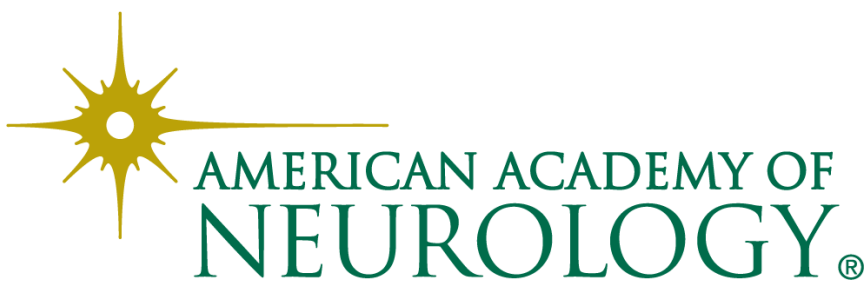

